\title{
Effects of Lunasia amara Blanco (Sanrego) on Male Fertility: A Preliminary Study on Sperm Proteomic Analysis
}

\author{
Muhammad Ja'far Luthfi, Amira Kamalrudin, Mahanem Mat Noor* \\ School of Biosciences and Biotechnology, Faculty of Science and Technology,UniversitiKebangsaan Malaysia, 43600 Bangi, Selangor, Malaysia.
}

\begin{tabular}{l} 
ARTICLE INFO \\
\hline Article history: \\
Received on: $18 / 03 / 2017$ \\
Accepted on: 09/06/2017 \\
Available online: $30 / 08 / 2017$ \\
\hline Key words: \\
Lunasia amara, sanrego, \\
proteomics, sperm proteins, \\
male fertility.
\end{tabular}

\begin{abstract}
Lunasia amara Blanco or sanrego has long been applied as a pro-fertility agent in folk medicine and it has also been scientifically proven to improve sperm quality in rats. Nevertheless, little is known about the underlying molecular mechanism of improved sperm function upon treatment with sanrego. As such, this study looked into the potential proteomic changes in sperm treated with $60 \mathrm{mg} / \mathrm{kg}$ body weight sanrego aqueous extract, in comparison to control. The sperm proteins were subjected to proteomic analysis using 2-D SDS PAGE and MALDI-TOF. The comparison of the sperm protein profiles between treated and control rats revealed two downregulated proteins (cenexin-1 and GLUL) and 11 upregulated proteins (Eno1,PGK2,F F $_{1}$ ATP synthase,

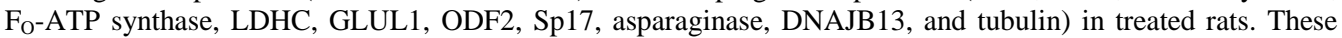
proteins have been identified to be mainly involved in energy metabolism, sperm motility, amino acid metabolism, and cell signalling. This improved sperm function in sanrego-treated rats may, thus, be a direct result of proteomic changes, as discovered in this present study.
\end{abstract}

\section{INTRODUCTION}

Approximately $50 \%$ of issues pertaining to infertility faced by couples worldwide have been due to male factors (Agarwal et al., 2015). Nonetheless, modern medical interventions for treatment of male infertility, such as assisted reproductive technology, are not only costly, but may also cause negative side effects (Dyer et al., 2016). Therefore, the limited availability of accessible and affordable therapies for male infertility has increased the demand for exploration of alternative treatments. One instance of such alternative treatment is the use of Lunasia amara Blanco, also known as sanrego, which has long been used in folk medicine as a pro-fertility agent in Southeast Asia (Cahyaningsih, 2016). Moreover, it has been

\section{Corresponding Author}

Mahanem Mat Noor, School of Biosciences and Biotechnology, Faculty of Science and Technology, UniversitiKebangsaan Malaysia, 43600

Bangi, Selangor, Malaysia. Email: mahanem @ ukm.edu.my believed that sanrego increases male fertility by stimulating the male reproductive organs that influence the sperm quality. In fact, a few studies have investigated the effects of sanrego on male fertility. For instance, Rahmat and Noor (2015) demonstrated that sanrego extract significantly increased male fertility and libido by elevating testosterone level and antioxidant enzymes activity. Prior to that, Luthfi and Noor (2009) reported that the aqueous extract of sanrego increased male fertility at doses of 30,60 , and $90 \mathrm{mg} / \mathrm{kg}$ body weight, in which treatment at $60 \mathrm{mg} / \mathrm{kg}$ body weight emerged as the most effective dose as it greatly improved sperm count, morphology, and motility. In spite of these, the effect of sanrego upon sperm quality at the protein level is yet to be understood. Sperm differentiation and maturation are resulted from a series of events in the male reproductive tract that involve changes in sperm protein profile, whereby the new proteins get attached to the membrane while the existing proteins undergo post-translational modification (Chocu et al., 2012). The sperm protein analysis, from the aspect of comparative proteomics, has allowed quantification of sperm protein concentration under various experimental conditions. 
On top of that, protein functions are associated with specific cellular processes and this information can be used with basic biochemistry and physiology to comprehend the biological processes. However, unlike genome, proteome is more dynamic and offers a clearer picture of the sperm biological status in response to diseases and treatment (Aebersold and Mann, 2016). A systematic analysis of comparative proteomic changes involves a series of experimental approaches of protein separation, protein digestion, and mass spectrometric peptide identification (Westermeier, 2016).

The present study, thus, employed isoelectric focusing and 2-D gel electrophoresis to separate the sperm proteins on polyacrylamide gel to allow both qualitative and quantitative comparisons of protein expression pattern between the samples. Next, the selected protein spots were excised from the gel and identified using MALDI-TOF. This study investigated the differences in sperm protein expression between sanrego-treated and control rats to comprehend partly the mechanism of sanrego in improving sperm quality, as well as fertility at the protein level.

These findings are deemed important for novel drug target development and therapeutic strategy using sanrego especially to treat male infertility.

\section{MATERIALS AND METHODS}

\section{Collection of plant material and preparation of aqueous extract}

Sanrego plants were collected from South Sulawesi, Indonesia and authenticated by Joko Santosa, a botanist from the Department of Pharmacy Biology, University of Gadjah Mada, Indonesia. The plant voucher (53/BFAR/020307) was deposited at the department. Next, the aqueous extract was prepared by using a traditional method, as suggested by Gonzales et al. (2006) with modification. The sanrego stems were washed, dried, and powdered. A total of $500 \mathrm{~g}$ of sanrego powder was boiled in 1500 $\mathrm{ml}$ distilled water for 30 minutes. The extract was filtered, freezedried, and kept at $-20^{\circ} \mathrm{C}$ untilfurther use. The extract was weighed according to dosage and dissolved in normal saline.

\section{Experimental animals}

12-week-old male Sprague-Dawley rats were obtained from the Animal House, Universiti Kebangsaan Malaysia, Malaysia. These rats were divided into two groups ( $n=5)$. Group 1 that functioned as control was given vehicle (distilled water, $1 \mathrm{ml}$ ), while group 2 was fed with the aqueous extract of sanrego at a dose of $60 \mathrm{mg} / \mathrm{kg}$ body weight. $1 \mathrm{ml}$ of sanrego aqueous extract was given by force-feeding once a day between 10.00 and 11.00 a.m. for 42 consecutive days. Upon completion of treatment, the rats were dissected to isolate the cauda epididymis. The experimental protocol was approved by the Animal Ethics Committee of Universiti Kebangsaan Malaysia (Approval number: FST/2013/MAHANEM/31-JAN./492-FEB.-2013-FEB.-2015).

\section{Extraction of sperm proteins}

Cauda epididymis was minced and incubated in $50 \mathrm{~mL}$ Biggers, Whitten, andWhittingham (BWW) medium (94.5 $\mathrm{mMNaCl}, 4.8 \mathrm{mMKCl}, 1.7 \mathrm{mM} \mathrm{CaCl}_{2}, 1.2 \mathrm{mM} \mathrm{MgSO}_{4} .7 \mathrm{H}_{2} \mathrm{O}, 25$ $\mathrm{mM} \mathrm{NaHCO}, 0.25 \mathrm{mM}$ sodium pyruvate, $21.6 \mathrm{mM}$ sodium lactate, $6 \mathrm{mM}$ glucose, $10 \mathrm{mM}$ HEPES, $35 \mathrm{mg} / \mathrm{ml}$ albumin, $\mathrm{pH}$ 7.4)for 30 minutes at $37^{\circ} \mathrm{C}$ in a $5 \% \mathrm{CO}_{2}$ incubator to activate the sperms. Sperm suspension was centrifuged $\left(3500 \times \mathrm{g}, 15 \mathrm{~min}, 24^{\circ} \mathrm{C}\right)$ and the supernatant was removed. Next, pellet was homogenized in a sterile tube containing lysis solution (8 M urea, 4\% CHAPS, $2 \%$ imobiline $\mathrm{pH}$ gradient buffer, $1 \mathrm{mM}$ phenylmethylsulfonyl fluoride, $1 \mathrm{mM}$ benzamidine). After that, the homogenate was incubated for 1 hour prior to centrifugation $\left(1500 \times \mathrm{g}, 2 \mathrm{~min}, 4^{\circ} \mathrm{C}\right)$. $60 \mathrm{mMof}$ dithiothreitol was added into the resulting supernatant. The protein concentration was determined by Bradford protein assay.

\section{2-D SDS PAGE}

Isoelectric focusing (IEF) was conducted on 7-cm IPG Strips with an EttanIPGphor Isoelectric system (Amersham Biosciences). The protein samples $(50 \mu \mathrm{l})$ were added to the immobilized $\mathrm{pH}$ gradient (IPG) strips and actively rehydrated for 12 hours at $20^{\circ} \mathrm{C}$ with the use of $50 \mu \mathrm{A} /$ strip. The IEF was carried out in three stages: $250 \mathrm{~V} / \mathrm{h}, 500 \mathrm{~V} / \mathrm{h}$, and $8333 \mathrm{~V} / \mathrm{h}$. After the first dimension, the strips were equilibratedby using a 3D rotator machine (Lab-Line) for 15 minutes in an equilibration buffer (50 mM Tris- $\mathrm{HCl}, \mathrm{pH} 8.8,6 \mathrm{M}$ urea, 30\% glycerol, 2\% SDS, $0.002 \%$ bromophenol blue)supplemented with $65 \mathrm{mM}$ dithiothreitol (DTT). This was followed by the second 15-minute equilibration with $0.135 \mathrm{M}$ indolacetic acid, instead of DTT. The second dimension of the SDS-PAGE was then conducted at $100 \mathrm{~V}$ and $20 \mathrm{~mA}$ by Hoefer mini VE (Amersham Bioscience). The $12.5 \%$ of polyacrylamide gels were prepared by adhering to the method proposed by Laemmli (1970). After electrophoresis, the 2 DE gels were stained with coomassie Brilliant Blue R-250 solution (Bio-Rad) and were kept at room temperature overnight to allow visualization of the proteins. Digital images of the 2-DE gels were acquired using an Image Scanner II (Amersham Bioscience), while the protein spots were analysed by using ImageMaster 2D platinum software version 5.0 (Amersham Bioscience). Lastly, any emerging protein spots were considered as significantly different in expression if they exhibited significant changes of at least a 1.5 fold.

\section{Matrix assisted laser desorption/ionization-time of flight mass spectrometry (MALDI-TOF)}

All statistically significant $(\mathrm{p}<0.05)$ spots were excised for in-gel digestion with trypsin and kept in Eppendorf tube containing deionized water to be sent to Proteomic Centre National University of Singapore for mass spectrometry analysis. The mass spectrum was acquired by using MALDI-Tof-Tof MS: 4800 Proteomics Analyzer, S/N AK01860603 (Applied Biosystems). These MS spectra were acquired in a reflector- 
positive mode over the range of $800-4000$ Da.Next, the MS data were analysed using GPS Explorer software Version 3.6 (Applied Biosystems) with default parameters. The proteins were searched against the NCBInr database using MASCOT search engine (Matrix Science). The identification of proteins had been based on $95 \%$ or higher confidence interval in their MASCOT scores. Hence, protein scores exceeding $40(\mathrm{p}<0.05)$ indicate extensive homology.

\section{RESULTS}

The overall treatment with sanrego revealed some changes in the expression of a number of sperm proteins. A total of 282 protein spots resolved in 2-DE gel of the treated group matched with the control group. Nevertheless, the ImageMaster5.0 software analysis portrayed significant difference of at least a 1.5 fold $(\mathrm{p}<0.05)$ in the expression of some 16 protein spots between treated and control groups. These 16 protein spots were assigned numbers; from 1 to 16, as shown in Fig. 1.

The differentially expressed proteins were then successfully identified with the Mascot score $>40$ (confidence interval >95\%). Three identified proteins were found to be expressed at two different spots; cenexin-1 (Spots 1 and 12), ODF2 (Spots 2 and 3), and Eno1(Spots 4 and 11). The identification of proteins with multiple spots on 2-DE gel is rather common in SDS-PAGE analysis due to the formation of protein isoforms that result from post-translational modification (Kleinert et al., 2006). Fig. 2 shows the differential expression of 13identified proteins on magnified 2-DE gel maps; enolase 1 (Eno1); phosphoglycerate kinase 2 (PGK2); ATP synthase, $\mathrm{H}^{+}$transporting, mitochondrial $\mathrm{F} 1$ complex, alpha subunit, isoform 1, isoform CRA_d ( $\mathrm{F}_{1}$-ATP synthase); ATP synthase, $\mathrm{H}_{+}$transporting, mitochondrial $\mathrm{FO}$ complex, subunit $\mathrm{d}$ ( $\mathrm{F}_{\mathrm{O}}$-ATP synthase); L-lactate dehydrogenase $\mathrm{C}$ (LDHC); DnaJ (Hsp40) related, subfamily $\mathrm{B}$, member 13 (DNAJB13); outer dense fibre of sperm tails 2, isoform CRA_b (ODF2); tubulin $\beta 2 \mathrm{c}$; glutamine synthetase 1 (GLUL1); sperm autoantigenic protein 17 (Sp17); asparaginase-like 1; cenexin-1; and glutamine synthetase (GLUL). Out of all these 13 different proteins, 11 displayed increment in abundancein the treatment group; ODF2 (Spots 2 and 3), Eno1 (Spots 4 and 11), GLUL1 (Spot 5), PGK2 (Spot 7), LDHC (Spot 8), DNAJB13 (Spot 9), F -ATP synthase (Spot 10), asparaginase (Spot 13), Sp17 (Spot 14), tubulin (Spot 15), and $\mathrm{F}_{\mathrm{O}^{-}}$ ATP synthase (Spot 16). Meanwhile, the other two proteins were found to be significantly downregulated; cenexin (Spots 1 and 12) and GLUL (Spot 6).

All these proteins had been identified to be involved in different functions. Five proteins (Eno1, PGK2, F 1 -ATP synthase, $\mathrm{F}_{\mathrm{O}}$-ATP synthase, and LDHC) functioned as enzymes in energy metabolism. Four proteins (cenexin-1, DNAJB13, ODF2, and tubulin) were structural proteins that possessed crucial function in sperm motility, whereas the remaining two (GLUL1 and GLUL) were involved in amino acid metabolism. Two signalling proteins (Sp17 and asparaginase) involved in fertilization were also identified. Information concerning these proteins is summarized in Table 1 .
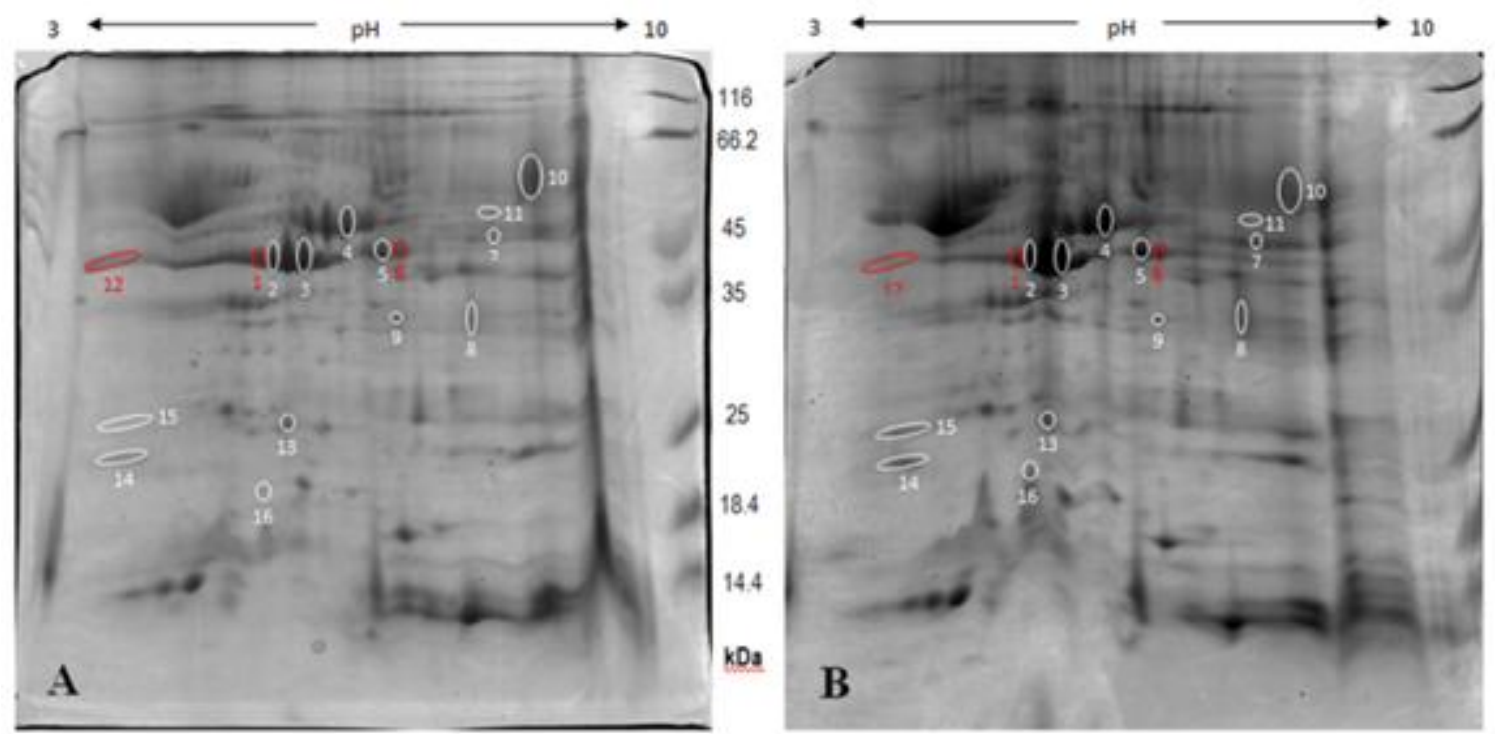

Fig. 1: Images of protein spots on 2-DE gels marked with their assigned number indicate significant altered expression of proteins between (A) control and (B) sanrego-treated groups. The upregulated proteins are indicated with white circles, while the downregulated proteins are marked in red circles. 

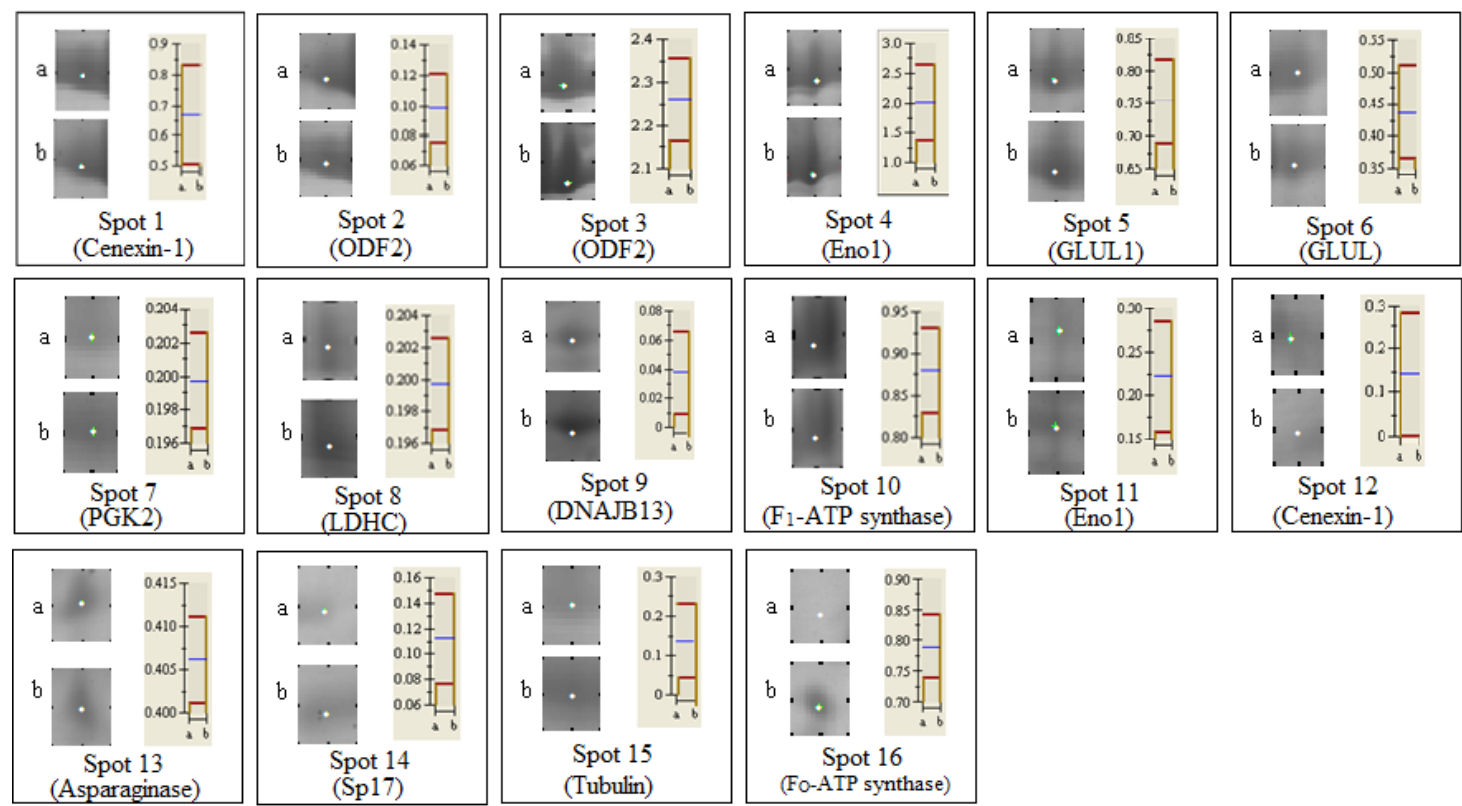

Fig. 2: Magnified 2-DE gel maps of differentially expressed protein spots. The analysis of protein spots for (a) control and (b) treated groups shows significant differential protein expression based on relative volumes. The graphic shows quantification value of relative volumes of protein spots. The white marks display the location of protein spots.

Table 1: List of differentially expressed protein spots in treatment group compared to control.

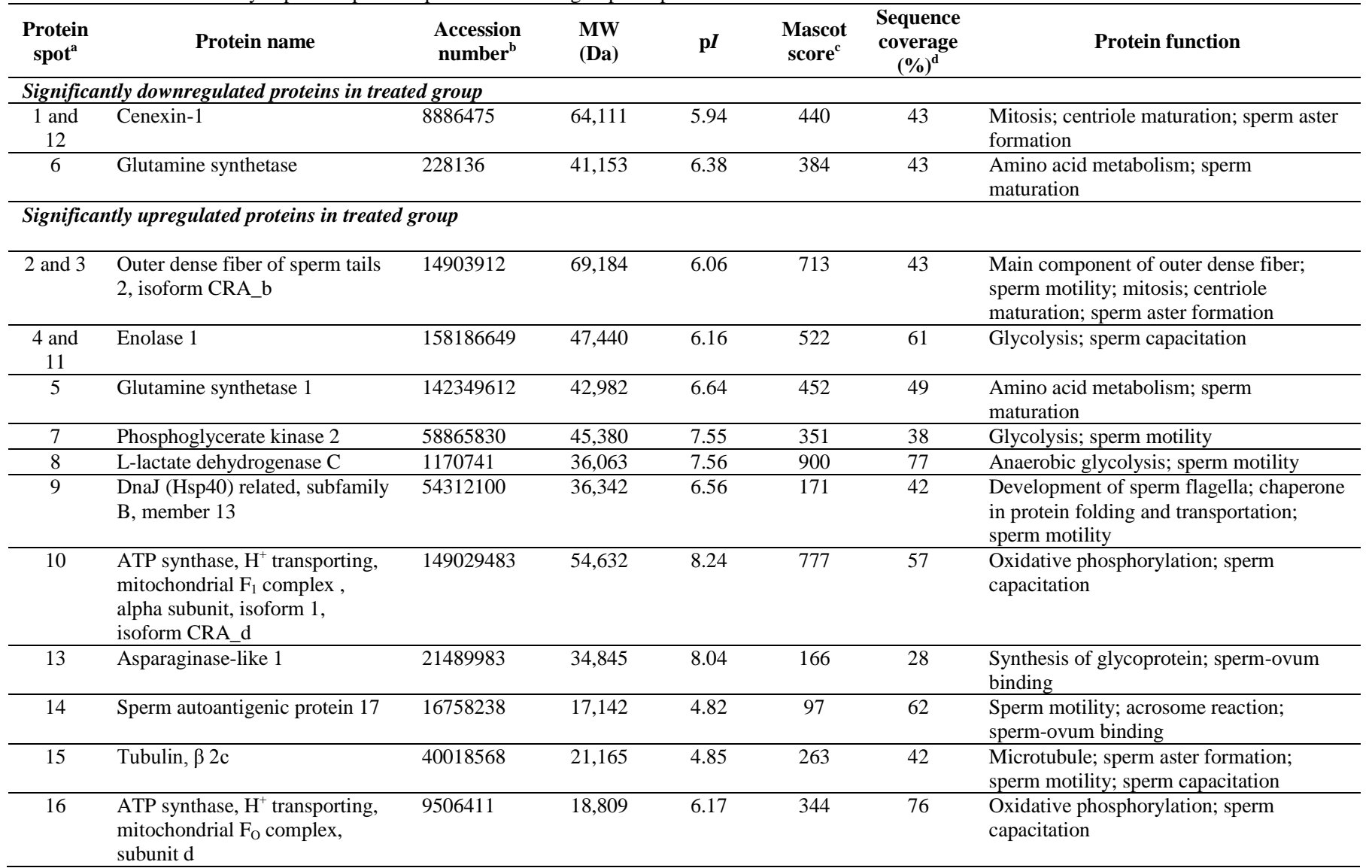

\footnotetext{
assigned spot ID as indicated in Figure 1

${ }^{b}$ NCBInr ID accession number

${ }^{\mathrm{c}}$ MASCOT score reported

${ }^{\mathrm{d}}$ Percentage of the identified protein sequence covered by the matched peptide
} 


\section{DISCUSSION}

It was previously reported that $60 \mathrm{mg} / \mathrm{kg}$ body weight sanrego extract significantly increased sperm quality from the aspects of morphology, motility, and viability (Luthfi, 2015). Such results may be interpreted as a consequence of altered protein expression, as observed in this present study. The differences in the expression of proteins between control and treated rats may influence physiology and fertilizability of sperm that should function as a mechanism to improve fertility. As such, these proteins are classified according to their functions in sperm; I) energy metabolism, II) sperm motility, III) amino acid metabolism, and IV) cell signalling.

\section{I) Energy metabolism}

Sperm uses both glycolysis and oxidative phosphorylation pathways to produce ATP. In precise, pyruvate is generated when glucose is broken down during glycolysis. The pyruvate enters the mitochondria in order to be fully oxidized by the Krebs cycle and oxidative phosphorylation. Along this process, abundance of ATP is produced. Eno1 and PGK2 are among the main glycolytic enzymes in sperm. Enol catalyses the conversion of 2-phosphoglycerate to phosphoenolpyruvate, which eventually converts one glucose molecule to two pyruvate and two ATP molecules (Piomboni et al., 2012). Meanwhile, PGK2 catalyses the conversion of 1.3 diphosphoglycerate to 3 phosphoglycerate to produce one molecule of ATP. This is because; ATP is needed to convert the glucose or fructose to pyruvate so as to provide energy required for sperm motility (Tourmente et al., 2015). In addition, Liu et al. (2016) demonstrated that PGK2 is significant for motility of hyperactive sperm. Oxidative phosphorylation preserves sperm motility in the absence of exogenous substrate. Thus, approximately $30-40 \%$ energy produced by this process is used directly for sperm motility (Bahmanzadeh et al., 2008). Additionally, ATP synthase and LDHC play important roles in sperm oxidative phosphorylation. ATP synthase is classified into $F_{0}$-ATP synthase and $\mathrm{F}_{1}$-ATP synthaseas they work together to synthesize ATP from ADP and inorganic phosphate. ATP synthase provides continuous ATP supply, which is critical for sperm motility (Kamali Sangani et al., 2016). On the other hand, LDHC makes it possible for the lactic acid produced by glycolysis to be directly oxidized. Hence, LDHC has a vital role in the preservation of progressive and hyperactive motility of the sperm (Tang et al., 2013). Moreover, this finding is in agreement with a clinical study performed by Odet et al.,(2008) who found that LDHC gene is absent from sperm of infertile male. Therefore, the increased expression of proteins involved in energy production may contribute in part to the increased sperm motility, as Luthfi (2015) reported that rats treated with $60 \mathrm{mg} / \mathrm{kg}$ body weight sanrego aqueous extract demonstrated grade A movement, while grade B movement for the control group.

\section{ii) Sperm motility}

DNAJB13 is a co-chaperone protein for HSP70 in the transportation and the translocation processes of proteins across membrane. Hence, the absence of DNAJB13 inhibits sperm capacitation and acrosomal reaction (Kumar et al., 20016). With that, the improved fertility of the treated rats could be explained by the increased expression of DNAJB13. In addition, DNAJB13 is a radial spoke protein found together with tubulin along the flagella of mature sperm. This radial spoke protein is a complex macromolecule that is needed in the regulation of sperm motility (Li and Liu, 2014). Tubulin, ODF2, and cenexin-1 are structural proteins involved in the formation of sperm aster to allow sperm maturation and motility (Francou et al., 2014). Any disruption in the functions of tubulin and ODF2 as the main cytoskeleton structures may hinder sperm motility (Toye et al., 2016). Meanwhile, cenexin-1 is an isoform of ODF2 located in centrosome and it plays an essential role in the regulation of mitosis. In fact, this present study revealed thatthe expression of cenexin-1 is downregulated in the treatment group compared to that of control. Despite of the downregulation of this protein, the sperm quality of the treated group was not affected (Luthfi, 2015). This could be due to the presence of upregulated ODF2 and tubulin, which both possess similar function as cenexin-1.

\section{iii) Amino acid metabolism}

GLUL is an enzyme that can be found around the sperm nucleus as it helps to protect the genome and it is involved in oocyte fertilization (Francou et al., 2012). It is also abundantly available in caput epididymis to regulate luminal acid-base balance, eliminate aluminium or glutamate from the lumen, and prepare the glutamine for amino acid and nucleotide formation in order to preserve the microenvironment needed for sperm maturation (Sharma et al., 2013). Meanwhile, this particular study discovered downregulation of GLUL and upregulation of GLUL1in the treated group. It could, therefore, be suggested that the improved fertility of the treated group may be contributed by overexpression of GLUL1. This could be due to the fact that both of these enzymes come from the same family enzyme, thus their effects are perhaps counterbalanced.

\section{iv) Cell signalling}

Sp17 is a surface membrane protein available on the head and tail of mature sperm. Sp17 found on the fibre sheath of sperm tail interacts with A-kinase anchor protein (AKAP3) and has a significant function as a signalling protein in protein kinase A-A kinase anchoring protein (PKA-AKAP) complex. Moreover, the binding of Sp17 to AKAP on sperm flagella shows that Sp17 regulates sperm motility via $\mathrm{Ca}^{2+}$ channel mechanism. Sp17 on the cell surface of sperm head binds to carbohydrate on zona pellucida during fertilization. The protein is characterized by its involvement in the binding of sperm to the zona pellucida of the oocyte(Reyeslópez et al., 2012). Other than that, asparaginase is also involved in the biosynthesis of sperm glycoprotein. During fertilization, asparaginase plays a role in the glycosylation of ZP3 protein, which refers to a sperm receptor involved in sperm-oocyte binding. ZP3 will then induce the acrosomal reaction that enables the sperm plasma membrane to fuse with oolema (Baker et al., 
2008). These findings signify that the improved fertility of sanrego-treated rats could also be due to the increased expression of $\mathrm{Sp} 17$ and asparaginase proteins.

The summary of the molecular mechanism of sanrego in improving male fertility is shown in Fig.3. Sperm maturation is influenced by GLUL and ODF2. ODF2 controls the function of sperm centriole and centrosome. Therefore, the absence of ODF2 results in the abnormality of the centrosome function, which may eventually affect the processes of mitosis, chromosomal segregation, and normal cell cycle (Toye et al., 2016). Following ejaculation, Eno1, ATP synthase, and tubulin regulate the sperm capacitation. Besides, a prior study demonstrated that sperm undergoing capacitation displayed increased expression of Eno1 (Choi et al., 2008). The level of sperm motility required in the female reproductive tract is determined by ODF2, PGK2, LDHC, DNAJB13, Sp17, and tubulin. As the sperm comes in contact with zona pellucida, asparaginase has a significant function in the formation of glycoprotein needed for sperm-zona pellucida binding (Baker et al., 2008). Other than that, Sp17 is crucial in acrosomal reaction and membrane fusion between sperm and oocyte. Further sperm-oocyte interaction and first embryo cleavage are determined by sperm aster formation regulated by tubulin and ODF2 (Francou et al., 2014).

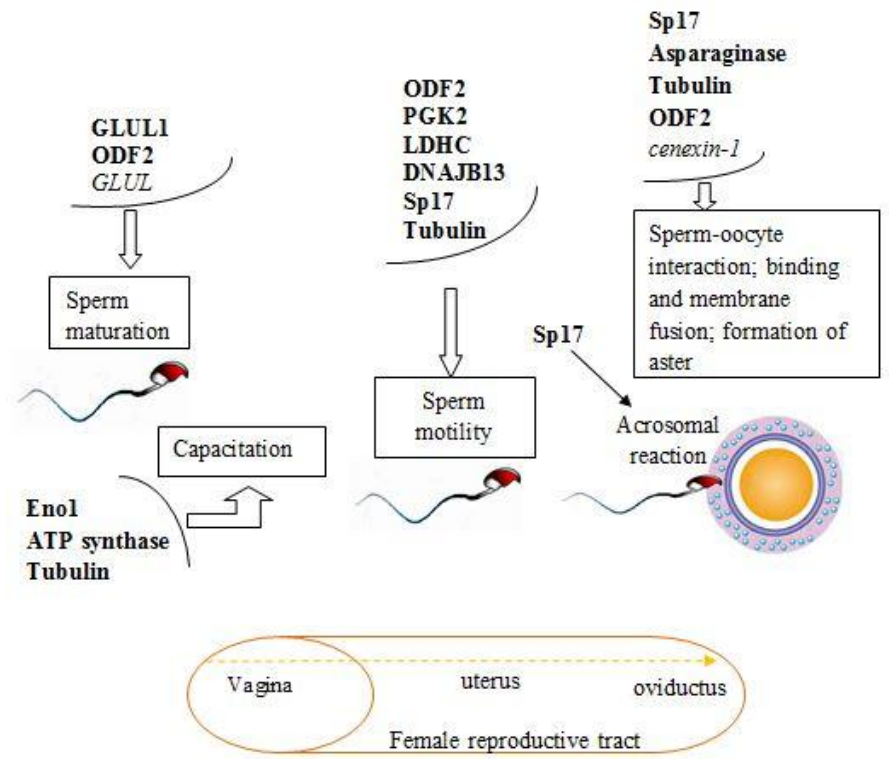

Fig. 3: Schematic presentation of sperm physiology and fertilizability in sanrego-treated rats, influenced by differential protein expression, which could be the potential mechanism to improve male fertility. Upregulated proteins are shown in bold, while downregulated proteins are shown in italic.

\section{CONCLUSION}

Proteomics is a useful tool to investigate the molecular mechanisms that regulate sperm function and for advancing our understanding pertaining to male fertility. It sheds light on the molecular basis of defective sperm function with implication for our ability to treat the rising issues related to fertility. As such, this present study, via sperm proteomics analysis, had successfully identified 11 upregulated sperm proteins (Eno1, PGK2, $F_{1}$-ATP synthase, $\mathrm{F}_{\mathrm{O}}$-ATP synthase, LDHC, GLUL1, ODF2, Sp17, asparaginase, DNAJB13, and tubulin) that may be the possible explanation for improved sperm quality of sanrego-treated rats as previously reported. The preliminary sperm proteome mapping, in order to understand fertility in relation to the effects of sanrego extract, may contribute to the development of therapeutics for male infertility. The proteomics approach, as undertaken in the present study, has opened avenues for further research on the development of potent phytochemicals in sanrego, as well as associated protein targets, to address male fertility.

\section{ACKNOWLEDGEMENT}

This work was financially supported by the Faculty of Science and Technology, Universiti Kebangsaan Malaysia.

\section{CONFLICT OF INTEREST}

The authors declared no potential conflicts of interest.

\section{REFERENCES}

Aebersold R, Mann M. Mass-spectrometric exploration of proteome structure and function. Nature, 2016; 537(7620): 347-355.

Agarwal A, Mulgund A, Hamada A, Chyatte MR. A unique view on male infertility around the globe. Reproductive Biology and Endocrinology, 2015; 13(1): 1-9.

Bahmanzadeh M, Abolhassani F, Amidi F, EjtemaiemehrSh, Salehi M, Abbasi M. The effects of nitric oxide synthase inhibitor (LNAME) on epididymal sperm count, motility, and morphology in varicocelized rats. DARU Journal of Pharmaceutical Sciences, 2008; 16(1): 23-28.

Baker M A, Hetherington L, Reeves G, Müller J, Aitken RJ. The rat sperm proteome characterized via IPG strip prefractionation and LC-MS/MS identification. Proteomics, 2008; 8: 2312-2321.

Cahyaningsih R. Characterization of phenotypic diversity of a medicinal plant Lunasiaamara. Nusantara Bioscience, 2016; 8(2): 245251.

Chocu S, Calvel P, Rolland AD, Pineau C. Spermatogenesis in mammals: proteomic insights. Systems biology in Reproductive Medicine, 2012; 58(4): 179-90.

Choi Y, Uhm S, Song S, Song H, Park J, Kim T, Park C, Kim $\mathrm{JH}$. Cytochrome c upregulation during capacitation and spontaneous acrosome reaction determines the fate of pig sperm cells: Linking proteome analysis. Journal of Reproduction and Development, 2008; 54(1): 68-83.

Dyer S, Chambers GM, De Mouzon J, Nygren KG, ZegersHochschild F, Mansour R, Ishihara O, Banker M, Adamson GD. International committee for monitoring assisted reproductive technologies world report: Assisted reproductive technology 2008, 2009 and 2010. Human Reproduction, 2016; 31(7): 1588-1609.

Francou MM, Ten J, Bernabeu R, De Juan J. Capacitation and acrosome reaction changes $\alpha$-tubulin immunodistribution in human spermatozoa. Reproductive BioMedicine Online, 2014; 28(2): 246-250.

Francou MM, Hombrebueno JR, De Juan J. Identification and cellular location of glutamine synthetase in human sperm. Cell and Tissue Research, 2012; 350(1): 183-187.

Gonzales C, Rubio J, Gasco M, Nieto J, Yucra S, Gonzales GF. Effect of short-term and long-term treatments with three ecotypes of Lepidiummeyenii (MACA) on spermatogenesis in rats. Journal of Ethnopharmacology, 2006; 103: 448-454.

Kamali Sangani A, Masoudi AA, VaezTorshizi R. Association of mitochondrial function and sperm progressivity in slow- and fastgrowing roosters. Poultry Science, 2016; 1-9. 
Kleinert P, Kuster T, Arnold D, Jaeken J, Heizmann CW, Troxler H. Effect of glycosylation on the protein pattern in 2-D-gel electrophoresis. Proteomics, 2006; 7(1): 15-22.

Kumar A, Singh J, Kumar R, Cheema RS, Pandey AK, Singh P, Ghuman SPS, BRAR PS, Gandotra VK. Prediction of buffalo bull fertility on the basis of sperm motion traits, viability, membrane integrity, heat shock protein (HSP70) expression and fertility associated antigen (FAA). Indian Journal of Animal Sciences, 2016; 86 (6): 648-654.

Laemmli UK. Cleavage of structural proteins during the assembly of the head of bacteriophage T4. Nature, 1970; 227: 681-685.

Li W. Liu G. DNAJB13, a type II HSP40 family member, localizes to the spermatids and spermatozoa during mouse spermatogenesis. BMC Developmental Biology, 2014; 14(38): 1-7.

Liu XX, Zhang H, Shen XF, Liu FJ, Liu J, Wang WJ. Characteristics of testis-specific phosphoglycerate kinase 2 and its association with human sperm quality. Human Reproduction,2016; 31(2): 273-9.

Luthfi MJ, Noor MM. KesanekstrakakuasLunasiaamara Blanco terhadapkualitispermakesuburandankelakuanseksualtikusjantan. SainsMal aysiana, 2009; 38(5): 793-797.

Luthfi MJ. Effect of Lunasiaamara Blanco on sperm number, sperm motility, and testicular histology of male rats. Biology Medicine, and Natural Product Chemistry, 2015; 4(2): 2089-6514.

Odet F, Duan C, Willis WD, Goulding EH, Kung A, Eddy EM, Goldberg E. Expression of the gene for mouse lactate dehydrogenase $\mathrm{C}$ (LDHC) is required for male fertility. Biology of Reproduction, 2008; 79(1): 26-34.

Piomboni P, Focarelli R, Stendardi A, Ferramosca A, Zara V. The role of mitochondria in energy production for human sperm motility. International Journal of Andrology, 2012; 35(2): 109-124.

Rahmat NR, Noor MM. Enhancement of fertility and libido in male spraguedawley rats following the administration of aqueous extract of Lunasiaamara. Malaysian Applied Biology, 2015; 44(1): 125-131.
Reyes-lópez M, Serrano-luna J, Piña-vázquez C, Garza MD, Aitken RJ, Nixon B, Abdelmohsen K. Ntwasa M, Tkahashi M, Iwaki D, Endo Y, Fujita T, Beisang D, Bohjanen PR, Bath JL, Ferris AE, Redgrove KA. 2012. Binding protein. Croatia: InTech.

Sharma R, Agarwal A, Mohanty G, Hamada AJ, Gopalan B, Willard B, Yadav S. Plesis S. Proteomic analysis of human spermatozoa proteins with oxidative stress. Reproductive Biology and Endocrinology, 2013; 1-18.

Tang H, Duan C, Bleher R, Goldberg E. Human lactate dehydrogenase A (LDHA) rescues mouse Ldhc-null sperm function. Biology of Reproduction, 2013; 88(4): 96.

Tourmente M, Villar-Moya P, Rial E, Roldan ERS. Differences in ATP generation via glycolysis and oxidative phosphorylation and relationships with sperm motility in mouse species. Journal of Biological Chemistry, 2015; 290(33): 20613-20626.

Toye AM, Parsons SF, Anstee DJ, Frayne J. Deficiency in Outer Dense Fiber 1 is a marker and potential driver of idiopathic male infertility. Molecular and Cellular Proteomics, 2016; 15(12): 3685-3693.

Westermeier R. 2D gel-based Proteomics: there's life in the old dog yet. Archives of Physiology and Biochemistry, 2016; 3455(April): 1-

\section{How to cite this article:}

Luthfi MJ, Kamalrudin A, Noor MM. Analysis of Sperm Proteomics Associated with the Effects of LunasiaamaraBlanco (Sanrego) on Male Fertility., J App Pharm Sci, 2017; 7 (08): 085091. 